\title{
Future perspective in BLSD training: The importance of peer-to peer education in high school students
}

\author{
Santomauro $\mathrm{M}^{1 *}$, Iaccarino $V^{2}$, Riganti $\mathrm{C}^{\mathbf{3}}$, Palma G ${ }^{1}$, Santomauro $\mathrm{MA}^{\mathbf{1}}$, Castellano $\mathrm{G}^{\mathbf{1}}$, Comentale $\mathrm{G}^{\mathbf{1}}$, Pilato $\mathrm{E}^{\mathbf{1}}$ and Iannelli $\mathrm{G}^{\mathbf{1}}$ \\ ${ }^{1}$ Department of Cardiovascular Emergency, Internal Medicine and Geriatric, School of Medicine and Surgery, "Federico II" University of Naples, Italy \\ ${ }^{2}$ Department of Cardiology, Sorrento Hospital - ASL NA3 Sud, Sorrento, Italy \\ ${ }^{3}$ Health Board Direction, Azienda Ospedaliera Universitaria, Naples, Italy
}

\begin{abstract}
Survival rate after a cardiac arrest strongly depends on the delay occurring from the onset of basic, and then advanced, life support procedures therefore a wide educational policy for all citizens to attend a BLSD training could improve survival on the territory. In this paper we presented the experience in BLSD training for adult. This work was a prospective observational study with an external blinded outcome evaluator to check the feasibility and efficacy of a peer to peer BLSD teaching to High school students compared to a professional led teaching.

Between 2010 and 2013, 320 High School 15-18 years old students were enrolled to receive a BLSD training for adult and then randomized into two groups (A and B): Group A ( $\mathrm{n}=156)$ had a peer to peer teaching while Group B $(\mathrm{N}=164)$ was trained in conventional way by a professional American Heart Association (AHA) certified instructor. At the end of training course, a final examination by a blinded instructor was held and results were analyzed. The item values were the percentage of the following parameters between two groups: check responsiveness, amount of calls to Territorial Emergency Service (118 for Italy), chest compressions with a correct hand position, adequate depth, correct rate, complete chest recoil by means of a Q-CPR (Quality cardiopulmonary Resuscitation) on the manikin used for CPR training, opening the Airway and giving breaths (head tilt-chin lift, mouth-to mouth breaths, mouth-to mask breaths), use of semiautomatic external defibrillator (AED) and retention of BLSD knowledge as assessed by 20-point questionnaire.

The analysis of results demonstrates that check responsiveness percentage was $97.6 \%$ in the peer-led group vs $96.7 \%$ in the professional-led group (p-value ns), that call 118 percentage was $95.8 \%$ in the peer-led group vs $96.8 \%$ in the professional-led group (p-value ns) and chest compressions (position hand, adequate depth, correct rate, complete chest recoil) percentage was $73.9 \%$ in the group A and $76.4 \%$ in the group B (p-value ns). Open the airway and giving breaths percentage was $30.4 \%$ in the Group A and $21.7 \%$ in the Group B ( $\mathrm{p}=0.05$ ). The automatic external defibrillator (AED) correct use percentage was 53.5\% in the peer-led group and $52.4 \%$ in the professional-led group (p-value ns). On the questionnaire administered after training, the peer-led group scored an average of $47.2 \%$ right answers in the Group A and of $49.8 \%$ in the Group B (p-value ns). The high school students who were trained by peer-instructors showed comparable skills in CPR for adult to those who were trained by professional instructors.
\end{abstract}

\section{Introduction}

Training CPR is a tough task especially in a common people that not have experience or knowledge about medicine and when the subject includes a practical skill and has an emotional feedback such as lifesaving. For these reasons, to extent BLSD training could be very challenging, especially if addressed at non-medical population and even more challenging when addressed to school students.

Sudden Cardiac Arrest (SCA) is a leading cause of death in the United States. Even if the estimated annual number of deaths due to out-of-hospital SCA vary widely, data from the Center for Disease Control and Prevention reports that in the United States approximately 330.000 people die annually from coronary heart disease before reaching hospital or emergency room; about 250.000 of those deaths occur in the out-of-hospital setting [1]. In Italy, this occurs in about 75.000 people [2].

CPR and defibrillation could really save lives when a cardiac arrest occurs, but in order to be effective they should be started as soon as possible and executed as best as possible. In fact, it is well known that survival decreases by $10 \%$ for each minute since the onset of a cardiac arrest. A lot of studies had shown a twofold increase in survival rate when a bystander provides an early CPR [1], so in order to improve survival rate more bystanders should be trained to BLSD organizing a social program to fight sudden cardiac death. Training people requires time, money and support from the Institution. In the latest years some experience in peer education and peer Medical education in schools have been carried out [3], so far it has been reported even training in primary School [4-10] and even in advanced cardiac life support [10]. In this study we wanted to compare a conventional teaching approach with a peer teaching approach for the training to BLSD of high schools students. In order to compare the two teaching methods, a QCPR feedback system for CPR quality was used and a questionnaire about the quality and efficacy of the teaching strategy was administered.

*Correspondence to: Maurizio Santomauro, MD, FESC, FHRS, Department of Cardiovascular Emergency, Internal Medicine and Geriatric, School of Medicine and Surgery, Federico II University, Via Sergio Pansini, 5 - 80131 Naples, Italy, E-mail: santomau@unina.it

Key words: Basic life support, peer education, defibrillator

Received: April 28, 2018; Accepted: May 11, 2018; Published: May 14, 2018 


\section{Project organization and methods}

Between years 2010-2013 in the cities of Naples and Sorrento a School program for BLSD training was started. A total of 11 courses had been used to compare peer-teaching and professional-teaching in 320 students (15-18 years old, 156 male and 164 female) from four high schools. None of them had been previously trained to BLSD, as confirmed by a pre-test administered to the students before the course. Pre-test was made up of 20-points questions regarding BLSD according to AHA and ILCOR (International Liaison Committee on Resuscitation) 2010 Guidelines for adult CPR [11]: both group obtained a very low score before the course, averaging between 3 and 5 correct answers $(30 \% \mathrm{c} / \mathrm{a})$. Inclusion criteria were volunteering to participate in the study and a minimum age of 15 years. The examinations of the students who suffered from any cognitive or physical disorder that made not safe and effective BLSD were excluded. Ten potential peerinstructors of 18 years old were recruited among the senior pupils and then attended a 2 day CPR Instructor Course at Federico II University (Naples). Instructors of the professional-led group were recruited from cardiologists and anesthesiology clinicians that have a AHA\&BLSDIstructor certification. Informed consent was obtained from the students and their parents before the start of training program that was approved by Sanitary Board Director of A.O.U. "Federico II". Almost 30 days before the course, ten students (belonging to another class from the training groups) were trained in a conventional way by BLSD instructor and their skill was confirmed by an exam after 21 days and one week before the School program was started. Two groups were formed and participants were randomized to Group A (peer Training) and Group $\mathrm{B}$ (conventional Training): each instructor had a 6 students group and a single training room. The course was organized according to AHA and ILCOR 2010 Guidelines [12] with 2-hours frontal lessons, videos and skill training (accounting for a total 6 hours lasting course). At the end of the course a theoretical exam with the same pre-test and a questionnaire referring to the BLSD course quality were administered. Skill exams were carried on by two different instructors blinded to the study. In addition, for CPR performance measures, a QCPR by Resusci Anne manikin (Laerdal Medical-Stavanger, Norway) was used that, through a Wireless SimPad SkillReporter, can report compression rate and depth, complete release, limited interruptions and appropriate ventilation volume.

Resusci Anne manikin skill tool was used in order to evaluate the quality of Check phase (i.e. responsiveness or no movement, Call EMS 118 - get AED), Opening Airway phase (i.e. head tilt chin lift maneuver, place ear near the victim's mouth and nose and look, listen and feel for breathing-take at least 5 and no more than $10 \mathrm{sec}$ ), Checking Breath phase (i.e. head tilt-chin lift, moth-to-mouth 2 breaths) efficacy of compressions over a full 2 minute CPR cycle (i.e. position hands, rate, depth and complete chest recoil). The safety algorhytm during the use of AED (i.e. list the steps common the operation of all AED, proper placement of the AED electrode pads, recall when pressing the shock button, no one should touch the victim while the AED is analyzing the heart rhythm or delivering a shock) (AED Philips HS1 trainer model) was checked.

\section{Course organization}

At first, students were trained to handle with an unconscious person using the "shake and shout" method to confirm unresponsiveness and then teached to immediately call the emergency number. Students were trained to procedures involving both one or two rescuers, teaching them to get AEDs when available, to start CPR immediately when an asphyxia arrest was expected and to act as leader or second rescuer.
Students were then trained to Head-tilt-chin-lift maneuver. Regarding to breathing assistance, they were taught just to search for life signs (cough, movement and breath). At the same time they were explained how to provide mouth to mouth breathing and mouth to mask breathing in a 30:2 odd. A significant attention was given to chest compression's teaching, suggesting the middle part of the chest as target for hand positioning and paying big attention on the concept "push hard and push fast": in fact, guidelines suggest a chest compression of at least $5 \mathrm{~cm} \mathrm{[12]} \mathrm{checked} \mathrm{through} \mathrm{CPR.} \mathrm{The} \mathrm{correct} \mathrm{use} \mathrm{and} \mathrm{timing} \mathrm{of}$ AED was explained and each of them was separately trained to its use.

\section{Statistical analysis}

Data were analyzed using a statistical software (SPSS for Windows, version 21, SPSS Inc, Chicago, IL). Results were expressed as mean \pm SD or percentage of students (\%) as appropriate. Paired t-test was used for within-group comparison of continuous variables between Group A and Group B. Groups differences were assessed by one way analysis of variance with post hoc Scheffe's test or Pearson $\mathrm{X}^{2}$ test as appropriate. Correlations of continuous variable were tested by Pearson's coefficient. A variable is entered into the model if $\mathrm{p} \leq$ 0.05 and is removed if $\mathrm{p} \leq 0.10$. P-values are two sided with $\mathrm{p} \leq 0.05$ considered to be statistically significant. A logistic regression model was used to detect the relationships between the primary endpoint and the demographic data.

\section{Results}

A total of 320 students were recruited from 4 high school for BLSD training during three CPR-awareness weeks and randomly assigned to the two groups. Four of the students left the event before their hands-on training. The data demonstrated that the two groups (peer-led training and professional-led training) were comparable for age, gender, height, weight and previous knowledge about CPR (Tables 1 and 2).

The principal outcome was the rate of passed skill examinations for each group. In the Group A 81,5\% of students passed the examination while in the Group B was $85,4 \%$ (p-value = n.s.). The logistic regression within the two groups showed no significant effect for the age, gender, height, weight, no CPR-training ever. On the contrary, regarding to the breathing-assisted phase the analysis of skill tests show that the pupils didn't ventilate correctly: the item failed in both groups regarding in particular the placing ear near mouth and nose (30.4\% vs $21.7 \%, \mathrm{p} \leq$ $0.05)$, mouth to mouth breaths $(31.0 \%$ vs $26.9 \% \mathrm{p} \leq 0.05)$ maneuvers. On the other hand, there was a significant difference in ensuring continues effective chest compression between two groups $(21.9 \%$ vs $18.5 \%, \mathrm{p} \leq 0.05$ ) (Table 3 ). The other results demonstrate that the rate of passed examination between the groups at all the items were comparable and did not differ significantly. Check responsiveness failed in $3.0 \%$ in the peer-led group and $3.8 \%$ in the professional-led group $(\mathrm{P} \leq 0.86)$. The call 118 percentage failed in $4.2 \%$ in the peer-led group and $3.2 \%$ in the professional-led group $(\mathrm{P} \leq 0.35)$. The percentage of chest compression in particular for ensure continues effective chest compression failed in $21.9 \%$ in the peer-led group and $18.5 \%$ in the professional-led group $(\mathrm{p} \leq 0.05$.). The percentage of failed use of AED, in particular analize no one should touch the victim was $6.0 \%$ in the peer-led group and $3.2 \%$ in the professional-led group $(p \leq 0.05)$. On the questionnaire administered after training, the peer-led group failed scored an average of $53.8 \%$ in the Group A and $47.2 \%$ in the Group B $(\mathrm{P} \leq 0.001)$. The $95 \% \mathrm{CI}$ of difference of the means was -1.72 to 0.57 . Results are summarized in Table 3. 
Table 1. Items of the skill examination

\begin{tabular}{|c|c|}
\hline Check & responsiveness or no movement \\
\hline Call EMS & calls 118 - get AED \\
\hline \multirow[t]{2}{*}{ Open Airway } & head tilt-chin lift maneuver \\
\hline & place ear near the victim's mouth and nose \\
\hline \multirow[t]{2}{*}{ Breaths } & head tilt-chin lift \\
\hline & moth-to-mouth breaths ( 2 breaths -1 sec each) \\
\hline Locating the Carotid Artery Pulse & unnecessary \\
\hline \multirow[t]{6}{*}{ Compress } & starts immediately \\
\hline & position hands \\
\hline & right compression frequency of $90-110 \mathrm{bpm}$ \\
\hline & right compression depth $(5 \mathrm{~cm})$ \\
\hline & complete chest recoil \\
\hline & ensures continues effective chest compression (No brake of more than $10 \mathrm{~s}$ ) \\
\hline \multirow[t]{4}{*}{ AED } & list the steps common the operation of all AED \\
\hline & proper placement of the AED electrode pads \\
\hline & recall when to press the shock button \\
\hline & no one should touch the victim while the AED is analyzing the HR or delivering a shock \\
\hline Questionnaire & 20 point \\
\hline
\end{tabular}

Table 2. Demographic data

\begin{tabular}{|l|c|c|c|}
\hline Characteristic & Group A (n=164) & Group B (n= 156) \\
\hline Age yr (SD) & $16,8+1.8$ & $15.9+2.1$ & $163+7.4$ \\
\hline Height-cm (SD) & $165,5+8.8$ & $63.7+9.8$ & n.s. \\
\hline Weight-kg (SD) & $66.7+10.1$ & $79(50,6 \%)$ & n.s. \\
\hline Male & $75(46 \%)$ & $155(99.3 \%)$ & n.s. \\
\hline No CPR training ever no & $157(95,7 \%)$ & n.s. \\
\hline
\end{tabular}

Table 3. Results for each failed item of the skill examination

\begin{tabular}{|c|c|c|c|c|c|}
\hline \multirow[t]{2}{*}{ Item } & \multicolumn{2}{|c|}{ Failure-rate Group A $(n=164)$} & \multicolumn{2}{|c|}{ Failure-rate Group B $(n=156)$} & \multirow{2}{*}{$\begin{array}{c}\text { p-value } \\
(\%)\end{array}$} \\
\hline & no & $(\%)$ & no & $(\%)$ & \\
\hline Check responsiveness & 5 & $3.00 \%$ & 6 & $3.80 \%$ & 0.86 \\
\hline Call EMS 118 - get AED & 7 & $4.20 \%$ & 5 & $3.20 \%$ & 0.35 \\
\hline Open Airway head tilt-chin lift maneuver & 18 & $10.90 \%$ & 15 & $9.60 \%$ & 0.9 \\
\hline Place ear near mouth and nose & 50 & $30.40 \%$ & 37 & $21.70 \%$ & 0.05 \\
\hline Breating head tilt-chin lift & 20 & $12.10 \%$ & 15 & $9.60 \%$ & 0.52 \\
\hline Moth-to-mouth 2 breaths & 51 & $31.00 \%$ & 42 & $26.90 \%$ & 0.05 \\
\hline Compressions Starts immediately & 4 & $2.40 \%$ & 2 & $1.20 \%$ & 0.8 \\
\hline position hands & 10 & $6.00 \%$ & 7 & $4.40 \%$ & 0.41 \\
\hline Right compression frequency of $90-110 \mathrm{bpm}$ & 19 & $11.50 \%$ & 14 & $8.90 \%$ & 0.86 \\
\hline Right compression depth $(5 \mathrm{~cm})$ & 23 & $14.00 \%$ & 19 & $12.10 \%$ & 0.69 \\
\hline complete chest recoil & 21 & $12.80 \%$ & 19 & $12.10 \%$ & 0.82 \\
\hline ensures continues effective chest compression & 36 & $21.90 \%$ & 29 & $18.50 \%$ & 0.05 \\
\hline AED power on & 5 & $3.00 \%$ & 4 & $2.50 \%$ & 0.8 \\
\hline placement of the AED electrode pads & 7 & $4.20 \%$ & 5 & $3.20 \%$ & 0.71 \\
\hline analize- no one should touch the victim & 10 & $6.00 \%$ & 5 & $3.20 \%$ & 0.05 \\
\hline clear and recall when to press the shock button & 7 & $4.20 \%$ & 5 & $3.20 \%$ & 0.82 \\
\hline
\end{tabular}

\section{Discussion}

Delivery of chest compressions is tiring, and the emphasis on fast, hard compressions makes it even more tiresome. Research has shown that compressions can become ineffective after to 5 minutes [11]. After their technique has deteriorated, rescuers may mistakenly believe they're still doing effective compressions for several minutes. In order to get the best and most effective compressions, AHA and ILCOR recommend that first responders rotate every 2 minutes, or at the end of every fifth cycle [11]. Healthcare providers have had "A-B-C" (airway, breathing, circulation) drilled into them, from the beginning of their career. It is thus common to prioritize the same way. Some suggest that rescuers should think the other way around. Researchers at the 2015 Consensus Conference reached several conclusion about chest compressions and the new AHA and ILCOR 2015 guidelines change the steps of CPR on "C-A-B" [12]. The highest priority is to maintain circulation with highquality chest compressions, then breathing, and then attention to airway as needed to facilitate breathing [12]. The order in which we approach unconsciousness should change the process. If a victim collapses due to a sudden cardiac event, high-quality compressions should be started while an AED is brought to their side whether the patient is pediatric or adult. Consider the circumstances of the collapse. If the victim is unresponsive from a respiratory event (most common in pediatrics) or from an airway obstruction, such as drowning, CPR should be performed for a period of 2 minutes prior to the application of an AED. The AED should be applied without interrupting compressions until it is possible to analyze the cardiac rhythm by the AED. Emergency Medical System (EMS) providers will seldom arrive in cardiac arrest while the 
victim is still in the electrical phase, unless bystander rescuers have provided immediate and continuous high-quality chest compressions, before attempting the defibrillation [11]. The recommendation for a defibrillation is one shock a time for patients in a shockable rhythm $[11,12]$. Research shows that the average hands-off time to deliver three shocks is about 40 seconds, which allows the coronary artery pressure to fall greatly [11]. This makes it important to continue compressions until you are ready to deliver a shock. There should be no more than 5 seconds from the time of the last compression to shock delivery for the most effective outcome. The increased coronary artery pressure will make the conversion more likely. After delivering a shock, there is no pulse check. Chest compressions should be started immediately and 2 minutes of CPR performed before a pulse check is done: in fact, even if the victim has an organized rhythm, the compressions will not harm the victim but, on the contrary, the victims benefits from the assistance because in the most of the time that a rhythm is present, cardiac output is still too low to provide adequate perfusion [11].

A main problem, in CPR performance, concerns quality of chest compression effected on the victim. The bystander rescuer, without training for critical emergency situation, easily could be emotionally involved: in this way quality of CPR performance is strongly reduced. Chest compression of at least $5 \mathrm{~cm}$ and chest compression rate of 100120 per minute make possible a good compression quality according new AHA and ILCOR 2015 Guidelines for BLSD [12]. Moreover, there is another important criterion in order to guarantee an effective performance: reducing as far as possible interruptions of chest compressions and reducing transition period from compressions to ventilations to a maximum of 10 seconds. Therefore, transition from compressions to ventilations (30:2) has to be as quick as possible in order to guarantee always at least 100-120 compressions per minute. By means of these directives CPR presents larger success probability and better recovery of vital functions [12]. Even knowing the sequences to perform a correct CPR, a bystander rescuer without training for CPR maneuvers, effecting transition from chest compressions to ventilations, takes a period longer than the 10 seconds which are necessary according to AHA and ILCOR Guidelines. Exceeding recommended period of 10 seconds, resuscitation success probabilities are reduced because recommended chest compression rate is not achieved.

The problem could be overcome by introducing "Hands-Only" CPR which prescribes elimination of pulmonary ventilations and is based on single performing of chest compressions. In fact "pulmonary ventilation factor" implies that many people are worried to be in contact with unwanted body fluids by means of mouth-to-mouth resuscitation or, even more, are worried to receive infectious diseases. Lester $C$ et al. [13] demonstrate by a questionnaire that the pupils expressed reluctance to resuscitate those with unpleasant physical characteristics: 160 (69\%) probably or definitely would not if vomit was present, 115 (49\%) if the casualty was dirty and 120 (52\%) if there was an unpleasant smell. These characteristics were reiterated in responses to the open-ended question. Other deterrents mentioned were bleeding in or around the mouth (54 respondents), serious injuries, dangerous situations for the rescuer, HIV-positive status, other known disease, being in a public place or a casualty unknown to the life supporter. This uncertainty reduces velocity of CPR maneuvers because rescuer takes longer time in considering risks. Mouth-to-mouth contact could, at the same time, slow down CPR beginning and increase interruption period between pulmonary compressions ( $>10$ seconds). Introducing "Hands-Only" CPR would reduce waiting periods before starting operations and, consequently, would guarantee the minimum number of chest compressions per minute. Mouth-to-mouth pulmonary ventilation effected by rescuer person provides oxygen percentage $(\%$ $\mathrm{O}_{2}$ ) of $16 \%$. Oxygen percentage in environmental air is of $21 \%$, while that provided by Ambu bag is of $40-50 \%$, up to a maximum of $90 \%$ if effected by supplementary mask with Reservoir. Oxygen percentage provided by Mouth-to-mouth ventilation is slight and, consequently, not necessary. In fact by means of simple chest compressions is possible to introduce a percentage of environmental air inside the lungs thanks to the difference of pressure due to the compressions themselves. This percentage would be sufficient until EMS rescue arrival and the study of Sayre RM, et al. [14] underlines that there are neither consequences nor neurological damages for lack of insufflations. There is a unique precaution to be considered: "Hands-Only" CPR is suitable just in case of pervious respiratory tract while, in case of respiratory arrest caused by mechanical obstruction or, for example, by acute asthma attack, the victim does not benefit from nontraditional CPR [12-15]. This demonstrates that First Aid maneuvers can be adapted and simplified depending on the context and on the victim. For a 15-18 aged student population, analyzed in our study, the omission of pulmonary ventilations is a further benefit because sequences are simplified and mouth-to-mouth risks are minimized. It is recommended as choice method for the untrained rescuer or those who are not proficient because it is easier to perform and instructions are easier to give over a phone. In adults with out-of-hospital cardiac arrest, compressiononly CPR done by a common person has an higher success rate than standard CPR. The exceptions are cases of drownings, apnea associated with drug overdose, trauma, airway obstruction, acute respiratory disease and arrest in infants and children.

Cabrini, et al. [16] demonstrate several reasons that could explain the best efficacy of chest compressiononly CPR. It is well documented that both interruptions of chest compressions during ventilation and positivepressure ventilations have detrimental effects on survival rate. Oxygenation and ventilation could be allowed, at least initially, by passive ventilation during chest compressions, by spontaneous gasping and by the lungs capacity to act as a reservoir. In addition, compressiononly CPR is easier to teach, to remember and to perform and it does not require mouthtomouth contact, so resulting in a better willingness to start CPR by bystanders. It is worth noting that in two of the three analyzed studies bystanders randomly assigned to standard CPR were significantly more likely to withhold CPR than bystanders assigned to compressiononly group. Results from our study, clearly shows that there is no difference in the quality of training between the two groups. But the only significative difference is on how the course is perceived. Students in Group A confirmed that they even enjoyed the course and most of them would participate to the retraining course. This such a difference could be as little for adults, but very significative whenever a School program should be started including even underage students and lasting 2-3 years with retraining. The comparison between the groups for the single item did not demonstrate any significant difference. Therefore, the CPR skills were equally effective in both groups. In addition such program, if started on a national base (including all High Schools), could represent a big problem for instructors, as they could result too few and not willing to do courses on each day of the year. In order to complete or to carry on such a big achievement, peer to peer education could prove very helpful, even though peer instructor should always be formed initially by professional instructors. This would avoid the perpetuation of mistakes and could be helpful to update peer instructor. Peer education is an interesting concept for the mass-training of students in CPR because it may reduce the costs and improve the students' learning. Involving peers in the training of 
students has a multiplicative effect that reduces the requirement of professionals. We selected the training by peers as a new intervention focused on the additional benefits of lower cost, greater availability of peers, and the additional training effect of the peers. In the present study breathing maneuver with mouth-to-mouth or mouth-to-barrier device has achieved low percentage in both groups (32\% vs $38 \%$ ). This result confirms that in peer CPR training performing "Hands-Only" method provides more benefit [14-16]. They've probably learned the following for simple steps: check no movement or response, phone 118 EMS, push hard and fast in the center of the chest, get AED.

The reported errors in ventilation and compression indicate that more practice was needed, preferably with the Laerdal QCPR manikin which gives feedback via colored lights for correct and incorrect performance. Failure to ventilate adequately is often caused by not maintaining an open airway, whilst compressions are often poor because the hands are incorrectly positioned on the sternum. The relatively high scores recorded during internal CPR skills assessment do not therefore imply that a rescue attempt by a pupil would have been successful, but merely demonstrate the proportion who performed as taught.

There are already some other papers that shows how peer education is effective for adults, but there is very little knowledge if this could work for high school students too [3-9]. It only remains unclear if the final exam should be always performed by a professional instructor. In fact, in our opinion being taught by a companion or someone with same age is one thing, but being tested is another thing. In addition, we are worried that a student could not be as objective as a professional instructor with his own school mate or friends, where maybe a student from another school could prove more objective. In our paper we had chosen instructor from different classes per group, but not from different school. In our peer experience we have tried to understand the feasibility of such a program and whether it eventually could be used on a large-scale program in Italy. Our study clearly shows no difference from 4 high school student. In this connection, a recent study [17] conducted in Germany has showed that peer-led CPR training for high school students is as effective as training by professionals $(40,3 \%$ in the peer-led group and $41 \%$ in the professional-led group passed the examination). Our study and that by Beck, et al. [17] are surprising because the professional instructors are characterized by having medical education and more previous experience in instructing others in CPR. Even though some paper already showed the feasibility of BLSD courses to young students and there is some data that even underage people could provide an effective chest compression for a limited time [10], we decided to test this system on 15-18 years old students, either because of informed consent either for body structure. Nonetheless we agree with previous experiences [18-51], and we strongly believe that younger high School students could provide a BLSD as good as last year high school students, but in this paper we have tried to avoid possible bias such as physical problem, consent problem, awerness and self-assessment. In fact, 15-18 years old students [10] are enough young to represent an high school student and are enough educated to understand the importance of an health care program especially for life savings technique. Recently, in Italy the Minister of Education, University and Research has included training CPR in Law n. 107 [52] for all seventh-grade students by the 118 EMS professional instructors. In this context, peer-led-training exceeds professional-led training due to its lower requirement of professional trainers and implying costsavings for school-based CPR training.

\section{Conclusions}

Peer led training in BLSD for High school Students is feasible and could be as effective as a professional led course. Moreover, in our opinion and experience peer led training shows a better feedback and trainee attitude when compared to conventional teaching. Finally, our data support that peer-led BLSD training could be a part of the educational goals in the secondary schools in Italy.

\section{Conflict of interest statement}

\section{None declared.}

\section{Acknowledgements}

This study would not have been possible without the support of the Gymnasium, Istituto Sacro Cuore Salesiani Napoli, Istituto Alberghiero Vico Equense, Istituto F. De Sanctis Alberghiero Napoli.

We are very grateful to the staff of Federico II Universit of Naples for their excellent instruction and organization, and to all pupils who took part in this study as tutors or as trainees.

\section{References}

1. Rea TD, Eisenberg MS, Sinibaldi G, White RD (2004) Incidence of EMS-treated outof-hospital cardiac arrest in the United States. Resuscitation 63: 17-24. [Crossref]

2. ISTAT Le principali cause di morte in Italia. Report 2012. Statistiche 2014; 1-18 www. istat.it

3. Herlitz J, Svensson L, Holmberg S, Angquist KA, Young M (2005) Efficacy of bystander CPR: intervention by lay people and by health care professionals. Resuscitation 66 : 291-295. [Crossref]

4. Fujiwara T, Nishimura M, Honda R, Nomoto M, Kobayashi N, et al. (2011) Comparison of peer-led versus professional-led training in basic life support for medical students Advances in medical educatione and practice Adv Med Educ Pract 2: 187-191. [Crossref]

5. Uray T, Lunzer A, Ochsenhofer A (2003) Feasibility of life-supporting first-aid (LSFA) training as a mandatory subject in primary schools. Resuscitation 59: 211-220.

6. Breckwoldt J, Beetz D, Schnitzer L, Waskow C, Arntz HR, et al (2007) Medica students teaching basic life support to school children as a required element of medical education: a randomised controlled study comparing three different approaches to fifth year medical training in emergency medicine. Resuscitation 74: 158-165.

7. Toner P, Connolly M, Laverty L, McGrath P, Connolly D, et al. (2007) Teaching basic life support to school children using medical students and teachers in a 'peer-training model - results of the 'ABC for life' programme. Resuscitation 75: 169-175.

8. Glynn LG, MacFarlane A, Kelly M, Cantillon P, Murphy AW (2006) Helping each other to learn a process evaluation of peer assisted learning. BMC-Med Educ 6: 18. [Crossref]

9. Perkins GD, Hulme J, Bion JF (2002) Peer-led resuscitation training for healthcare students: a randomised controlled study. Intensive Care Med 28: 698-700. [Crossref]

10. Hughes TC, Jiwaji Z, Lally K (2010) Advanced Cardiac Resuscitation Evaluation (ACRE): a randomized single-blind controlled trial of peer-led vs expert-led advanced resuscitation training. Scand J Trauma Resusc Emerg Med 18: 3.

11. Bhanji F, Mancini ME, Sinz E, Rodgers DL, McNeil MA, et al. (2010) Part 16: education, implementation, and teams: 2010 American Heart Association Guidelines for Cardiopulmonary Resuscitation and Emergency Cardiovascular Care. Circulation 122: S920-S933. [Crossref]

12. Neumar RW, Shuster M, Callaway CW, Gent LM, Atkins DL, et al. (2015) Executive Summary:2015 American Heart Association Guidelines Update for Cardiopulmonary Resuscitation and Emergency Cardiovascular Care. Circulation 132: S315-S367

13. Lester C, Donnelly P, Weston C (1997) Is pee tutorial beneficial in the context of schoo resuscitation training? Health Education Research 12: 347-354.

14. Sayre MR, Berg RA, Cave DM, Page RL, Potts J, et al. (2008) "Hands-Only (Compression-Only) Cardiopulmonary Resuscitation: A Call to Action for Bystander Response to Adults Who Experience Out-of-Hospital Sudden Cardiac Arrest". Circulation 117: 2162-2167. [Crossref] 
15. Hupfl M, Selig HF, Nagele P (2010) "Chestcompressiononly versus standard cardiopulmonary resuscitatio: a metaanalysis". Lancet 376:1552-7. [Crossref]

16. Cabrini L (2010) Bystanderinitiated chest compressiononly CPR is better than standard CPR in outofhospital cardiac arrest. HSR Proc Intensive Care Cardiovasc Anesth 2: 279-285. [Crossref]

17. Beck S, Issleib M, Daubmann A, Zollner C (2015) Peer education for BLS-training in schools? Results of a randomized-controlled, noninferiority trial. Resuscitation 94: $85-90$.

18. Jones I, Whitfield R, Colquhoun M, Chamberlain D, Vetter N, et al. (2007) At what age can schoolchildren provide effective chest compressions? An observational study from the Heartstart UK schools training programme. BMJ 334: 1201. [Crossref]

19. Robak O, Kulnig J, Sterz F (2006) CPR in medical schools: learning by teaching BLS to sudden cardiac death survivors-a promising strategy for medical students? BMC Med Educ 6: 27.

20. Anantharaman, V (2011) Developing resuscitation programmed in the community: The tasks ahead for the national resuscitation council. Singapore Medical Journal 52: 634641. [Crossref]

21. Blakemore S (2011) Children, parents and teachers back lessons in resuscitation Emergency Nurse : The Journal of the RCN Accident and Emergency Nursing Association 19: p5593.

22. Bohn A, Lukas RP, Breckwoldt J, Böttiger BW, Van Aken H (2015) 'Kids save lives': Why schoolchildren should train in cardiopulmonary resuscitation. Current Opinion in Critical Care 21: 220-225. [Crossref]

23. Bohn A, Van Aken H, Lukas RP, Weber T, Breckwoldt J (2013) School children as lifesavers in Europe - training in cardiopulmonary resuscitation for children. Best Practice \& Research. Clinical Anaesthesiology 27: 387-396.

24. Bottiger BW, Aken HV (2015) Training children in cardiopulmonary resuscitation worldwide. Lancet (London, England) 385.

25. Corrado G, Rovelli E, Beretta S, Santarone M, Ferrari G (2011) Cardiopulmonary resuscitation training in high-school adolescents by distributing personal manikins. the como-cuore experience in the area of como, italy. Journal of Cardiovascular Medicine (Hagerstown, Md.) 12: 249-254. [Crossref]

26. De Buck E, Van Remoortel H, Dieltjens T, Verstraeten H, Clarysse M (2015) Evidencebased educational pathway for the integration of first aid training in school curricula. Resuscitation 94: 8-22. [Crossref]

27. Estes NA $3^{\text {rd }}$ (2007) Prediction and prevention of sudden cardiac arrest: Lessons learned in schools. Circulation 116: 1341-1343 [Crossref]

28. Griesenbeck K (2011) Be the beat: A free CPR and AED resource for schools. NASN School Nurse 26: 92

29. Hart D, Flores-Medrano O, Brooks S, Buick JE, Morrison LJ (2013) Cardiopulmonary resuscitation and automatic external defibrillator training in schools: "is anyone learning how to save a life?". Cjem 15: 270-278. [Crossref]

30. Iserbyt P, Charlier N, Mols L (2014) Learning basic life support (BLS) with tablet PCs in reciprocal learning at school: Are videos superior to pictures? A randomized controlled trial. Resuscitation 85: 809-813 [Crossref]

31. Marco CA, Larkin GL (2003) Public education regarding resuscitation: Effects of a multimedia intervention. Ann Emerg Med 42: 256-260. [Crossref]

32. Lockey AS, Georgiou M (2013) Children can save lives. Resuscitation 84: 399-400.

33. McCluskey D, Moore P, Campbell S, Topping A (2010) Teaching CPR in secondary education: The opinions of head teachers in one region of the UK. Resuscitation 81 : 1601 .
34. Miro O, Diaz N, Escalad X, Pueyo PFJ, Sanchez M (2012) Review of initiatives carried out in spain to implement teaching of basic cardiopulmonary reanimation in schools. [Revision de las iniciativas llevadas a cabo en Espana para implementar la ensenanza de la reanimacion cardiopulmonar basica en las escuelas] Anales Del Sistema Sanitario De Navarra 35: 477-486.

35. Lockey AS, Georgiou M. (2013) Children can save lives. Resuscitation 84: 399-400

36. Maconochie I, Simpson S, Bingham B (2007) Teaching children basic life support skills. BMJ 334: 1174. [Crossref]

37. McCluskey D, Moore P, Campbell S, Topping A (2010) Teaching CPR in secondary education: The opinions of head teachers in one region of the UK. Resuscitation 81 : 1601.

38. Miro O, Diaz N, Escalada X, Pueyo PFJ, Sanchez M (2012) Review of initiatives carried out in spain to implement teaching of basic cardiopulmonary reanimation in schools. [Revision de las iniciativas llevadas a cabo en Espana para implementar la ensenanza de la reanimacion cardiopulmonar basica en las escuelas] Anales Del Sistema Sanitario De Navarra 35: 477-486.

39. Naqvi S, Siddiqi R, Hussain SA, Batool H, Arshad H (2011) School children training for basic life support. Journal of the College of Physicians and Surgeons--Pakistan JCPSP 21: 611-615.

40. Nicholls M (2006) Training children to save heart attack victims. Circulation 113: f60.

41. Oh J, Kang H, Lim T, Cho Y, Je S (2012) Use of mobile phones to stimulate interest and aid concentration for teaching resuscitation in schools. Resuscitation 83: e174. [Crossref]

42. Oulego-Erroz I, Busto-Cuinas M, García-Sanchez N, Rodríguez-Blanco S, RodríguezNunez A. A popular song improves CPR compression rate and skill retention by schoolchildren: A manikin trial. Resuscitation 82: 499-500. [Crossref]

43. Stroobants J, Monsieurs K, Devriendt B, Dreezen C, Vets P, Mols P (2014) Schoolchildren as BLS instructors for relatives and friends: Impact on attitude towards bystander CPR. Resuscitation 85: 1769-1774. [Crossref]

44. Tanaka H, Nakao A, Mizumoto H, Kinoshi T, Nakayama Y et al. (2011) CPR education in japan--past, present and future. Nihon Rinsho.Japanese Journal of Clinical Medicine 69: 658-669. [Crossref]

45. Raemdonck VV, Monsieurs KG, Aerenhouts D, De Martelaer K. Teaching basic life support: A prospective randomized study on low-cost training strategies in secondary schools. European Journal of Emergency Medicine 21: 284-290. [Crossref]

46. Vetter VL, Haley DM (2014) Secondary prevention of sudden cardiac death: Does it work in children? Current Opinion in Cardiology 29: 68-75. [Crossref]

47. Uray T, Lunzer A, Ochsenhofer A, Thanikkel L, Zingerle R, et al. (2003) Feasibility of life-supporting first-aid (LSFA) training as a mandatory subject in primary schools. Resuscitation 59: 211-220. [Crossref]

48. Vetter VL, Haley DM (2014) Secondary prevention of sudden cardiac death: Does it work in children? Current Opinion in Cardiology 29: 68-75

49. Bohn A, Lukas RP, Breckwoldt J, Böttiger BW, Van Aken H (2015) 'Kids save lives': why schoolchildren should train in cardiopulmonary resuscitation. Curr Opin Crit Care 21: 220-225. [Crossref]

50. Bottiger BW, Aken VH (2015) Training children in cardiopulmonary resuscitation worldwide. Lancet 13: 2353.

51. De Buck E, Van Remoortel H, Dieltjens T, Verstraeten H, Clarysse M, et al. (2015) Evidence-based educational pathway for the integration of first aid training in schoo curricula. Resuscitation 94: 8-22. [Crossref]

52. LEGGE 13 luglio 2015 , n. 107 : Riforma del sistema nazionale di istruzione formazione e delega per il riordino delle disposizioni legislative vigenti. Gazzetta Ufficiale Serie Generale n.162 del 15-7-2015 comma 10

Copyright: (C2018 Santomauro M. This is an open-access article distributed under the terms of the Creative Commons Attribution License, which permits unrestricted use, distribution, and reproduction in any medium, provided the original author and source are credited. 